\title{
The Relation Between Anthropometric Measurement and Physical Fitness in the Elderly Population
}

\author{
Cerika Rismayanthi ${ }^{1, *}$ Prijo Sudibjo ${ }^{1,}$ Krisnanda Dwi Apriyanto ${ }^{1,}$ Satya Perdana ${ }^{1}$
}

\author{
${ }^{1}$ Faculty of Sport Science, Universitas Negeri Yogyakarta, Indonesia \\ ${ }^{*}$ Corresponding author. Email: cerika@uny.ac.id
}

\begin{abstract}
Old age is human's final development stage. Aging in old age will bring consequences in deteriorating functions and increased prevalence of degenerative diseases in the elderly. To keep being productive, elderly people need to know about the importance of physical activities, anthropometric measurements, and physical fitness. The objective of the present study is to obtain data on anthropometric measurements, including waist size, hip circumference and waist size to hip circumference ratio and fitness status in the elderly population using 6 minutes walk. The present study is an observational analytical study performed using a cross sectional approach. The sampling used consecutive sampling method. The population and sample of the present study were Teratai Nogotirto Elderly Group, Nogotirto Urban Village, Gamping Sub-district, Sleman. The elderly people were 90 people coached by the Indonesian Doctor Association (IDI) and Indonesian Doctor's Wife Association (IIDI) of Yogyakarta. The research location was Nogotirto Village Meeting Hall, Nogotirto Urban Village, Gamping Sub-district, Sleman. The research instrument was an anthropometric measurement and physical fitness test. The instrument to collect data was a 6 minutes walk. The anthropometric data was waist size, hip circumference and waist size to hip circumference ratio measurements. The normality test was OneSample Kolmogorov-Smirnov Test, which showed that all data variables i.e. waist size, hip circumference and waist size to hip circumference ratio and 6 minutes walk, had normal data distribution. All data was normally distributed so that Pearson's correlation test was performed to determine whether there was any relation between anthropometric status and physical fitness. The Pearson's correlation test result showed that all research variables, i.e. waist size, hip circumference and waist size to hip circumference ratio, are $p<0,05$, in which waist size $(p=0.678)$, hip circumference $(p=0.391)$ and RLPP (0.537). The significance value $p<0.05$ shows that there was a significant correlation between waist size, hip circumference, and RLPP and physical fitness. It's concluded that there is no relation between waist size, hip circumference and waist size to hip circumference ratio and the physical fitness status of the elderly.
\end{abstract}

Keywords: Anthropometric Measurement, Fitnes Status, Elderly Population.

\section{INTRODUCTION}

Physical activity is a determining factor of metabolic syndromes because it affects obesity and fat distribution as well as inflammation process related to cardiovascular disease risk in old age. Moderate level of physical activity can lower blood pressure significantly in mild to moderate essential hypertension patients. The Pawtucket Study states that there is a significant relation between physical activity and increased HDL level. Physical activity will benefit the body if it meets FITT (frequency, intensity, time, type) criteria. Similarly, the physical activity of the elderly must meet the FITT criteria. Frequency refers to how often physical activity is performed, how many days in a week. Intensity refers to how hard a physical activity is performed, whether it's low, moderate or high intensity. Time refers to how long a physical activity is performed in a session. Physical activity types are aerobic and anaerobic. The suitable physical activities for the elderly are aerobics, muscle strengthening, flexibility and balance exercise. The amount of exercise depends on the purpose of each individual, e.g. independence, health, fitness, or performance improvement.

The suggested physical activities for the elderly were aerobics, flexibility exercise, muscle strength exercise and balance. At least 150 minutes of moderate physical activity every benefits elderly people [1]. Physical activities such as exercises have great benefits because they can improve elements of physical fitness, i.e. cardiovascular and respiratory systems, joint flexibility and muscle strength. Exercise can reduce the occurrence and severity of cardiovascular diseases, obesity, DM, 
hypertension, some joint, muscle and bone disorders, and stress. Individuals with low physical activity have a twice higher risk of metabolic syndromes than those with good physical activity [2], [3]. Physical activity is important to improve physical fitness and prevent metabolic syndromes. Based on the issue, the researchers would like to determine the relation between metabolic syndromes and fitness in the elderly.

Elderly people are recommended to perform at least 30 minutes of moderate physical activity every day in a week. Day to day activities such as walking, gardening, doing household chores and going up and down the stairs can help them reach their objective. People over the age of 65 should perform exercises which don't put too much burden on the bones, such as walking, water exercises, exercise bike, in a fun way. Elderly people who lack exercise should start with low intensity and increase individually based on tolerance to physical exercise. Aerobics are exercises which make the heart and lungs work harder to increase oxygen level, such as walking, biking, swimming. The exercise should be performed for at least 30 minutes at moderate intensity. Physical fitness is an individual's ability to meet ordinary and extraordinary demands in everyday life effectively without getting too tired and still having remaining energy for relaxation and recreation, [4]. Physical fitness is separated into two categories, which are skill related fitness and health related fitness. [5] states that health components include: (a) cardiorespiratory fitness, (b) body composition, (c) flexibility, (d) muscle strength and (e) muscle endurance. The physical fitness related to skill includes: (a) speed, (b) strength, (c) balance, (d) agility, (e) coordination, and (f) reaction time.

Physical activity is a determining factor of metabolic syndromes because it affects obesity and fat distribution as well as inflammation process related to cardiovascular disease risk in old age. Individuals with low physical activity have a twice higher risk of metabolic syndromes than those with good physical activity [2], [3]. Moderate level of physical activity can lower blood pressure significantly in mild to moderate essential hypertension patients.

\section{METHOD}

\subsection{Research Method}

The present study is an observational analytical study performed using a cross sectional approach, which is a type of research that emphasizes on data measurement or observation time at one time on dependent and independent variables. Observational analytical study is performed by observing without any treatment from the researchers. Population and Research Sample The sampling used consecutive sampling technique. The sample was all incoming subjects who met the selection criteria until the number of subjects was met. The research type was correlation. Teratai Nogotirto Elderly Group, Nogotirto Urban Village, Gamping Sub-district, Sleman. The elderly people were 90 people coached by the Indonesian Doctor Association (IDI) and Indonesian Doctor's Wife Association (IIDI) of Yogyakarta.

\subsection{Research Instrument}

The instrument to collect data was a 6 minutes walk. The anthropometric status was measured from waist size, hip circumference and waist size to hip circumference ratio. Central obesity was measured from belly circumference, resulting in over $90 \mathrm{~cm}$ for men and over $80 \mathrm{~cm}$ for women. The cut of point was used as a reference in the present study. Meanwhile, patient classification based on WHO's RLPP cut of point for Asians is $>0.95$ for men and $>0.80$ for women to indicate abdominal obesity.

\section{RESULTS}

The research sample was Teratai Nogotirto Elderly Group. The number of elderly people who completed the series of activities required in the present study was 90 people, consisting of 25 men and 65 women. The measurements in the present study were: waist size, hip circumference, waist size to hip circumference ratio and an elderly physical fitness test by walking for 6 minutes.

Table 1. Research subject description data

\begin{tabular}{|l|c|c|c|c|c|c|}
\hline \multicolumn{1}{|c|}{ Variable } & N & Min & Max & Mean & $\begin{array}{c}\text { Std. } \\
\text { Deviation }\end{array}$ & Variance \\
\hline Waist Size & 90 & 63 & 119 & 88.9556 & 11.10614 & 123.346 \\
\hline $\begin{array}{l}\text { Hip } \\
\text { Circumference }\end{array}$ & 90 & 79 & 130 & 98.0667 & 8.43987 & 71.231 \\
\hline RLPP & 90 & 0.72 & 1.06 & 0.9060 & 0.06618 & 0.004 \\
\hline 6 Minutes Walk & 90 & 120 & 555 & 372.81 & 83.298 & 6938.604 \\
\hline Valid N (listwise) & 90 & & & & & \\
\hline
\end{tabular}

The ninety elderly people who completed the series of research activities were 25 elderly men and 65 elderly women.

Table 2. Number of research subjects by gender

\begin{tabular}{|c|l|c|}
\hline No & \multicolumn{1}{|c|}{ Gender } & Amaount $(\mathrm{n})$ \\
\hline 1 & Man & 25 \\
\hline 2 & Woman & 65 \\
\hline \multicolumn{2}{|c|}{ Amaount } & 90 \\
\hline
\end{tabular}

Central obesity is an excess of adipose tissues in the abdominal area (intraabdominal fat), which can be determined from belly size with positive results for men over $90 \mathrm{~cm}$ and women over $80 \mathrm{~cm}$. The cut of point was used as a reference in the present study. 90 samples were measured to determine the relation between anthropometric status and physical fitness status. The 
waist size of 60 elderly people, which consisted of 10 elderly men and 50 elderly women, with central obesity were measured. 30 elderly people didn't have central obesity or were normal, consisting of 15 elderly men and women. The waist size data is presented in the table below.

Table 3. Number of elderly with central obesity measured at waist circumstances

\begin{tabular}{|c|l|c|c|c|}
\hline \multirow{2}{*}{ No } & \multirow{2}{*}{ Status } & \multicolumn{2}{|c|}{ Gender } & \multirow{2}{*}{ Amount } \\
\cline { 3 - 4 } & $\begin{array}{l}\text { Central } \\
\text { Obsesitaty }\end{array}$ & 10 & 50 & 60 \\
\hline 2 & Normal & 15 & 15 & 30 \\
\hline \multicolumn{2}{|c|}{ Amount } & 25 & 65 & 90 \\
\hline
\end{tabular}

The patient classification based on WHO's RLPP cut of point for Asians is $>0.95$ for men and $>0.80$ for women to indicate abdominal obesity. The cut of point was used as a reference in the present study. The abdominal obesity measurement by RLPP on 90 elderly people showed that 60 elderly people had abdominal obesity, consisting of 2 elderly men and 58 elderly women. Meanwhile, the 30 elderly people who didn't have abdominal obesity were 23 elderly men and 7 elderly women. The RLPP data of the elderly people is presented in the table below.

Table 4. The number of elderly who have central obesity measured at the wist circumstances

\begin{tabular}{|c|l|c|c|c|}
\hline \multirow{2}{*}{ No } & \multirow{2}{*}{ Status } & \multicolumn{2}{|c|}{ Gender } & \multirow{2}{*}{ Amount } \\
\cline { 3 - 4 } & $\begin{array}{l}\text { Abdominal } \\
\text { Obesity }\end{array}$ & 2 & 58 & 60 \\
\hline 2 & Normal & 23 & 7 & 30 \\
\hline \multicolumn{2}{|c|}{ Amount } & 25 & 65 & 90 \\
\hline
\end{tabular}

The physical fitness status of elderly people was measured by walking for 6 minutes. The distance was measured in meter. It was then compared with the norm table to categorize the physical fitness status. 90 elderly people joined the physical fitness test by walking for 6 minutes, and only 3 elderly women had a "normal" physical fitness level. The rest of the elderly people, both Male and female, had "below average" physical fitness.

Table 5. Elderly Fitness Level

\begin{tabular}{|c|c|c|c|c|c|}
\hline \multirow[b]{2}{*}{ No } & \multirow[b]{2}{*}{ Gender } & \multicolumn{3}{|c|}{ Gender } & \multirow[b]{2}{*}{ Amount } \\
\hline & & $\begin{array}{c}\text { Below } \\
\text { Average }\end{array}$ & Normal & $\begin{array}{c}\text { Above } \\
\text { Average }\end{array}$ & \\
\hline 1 & Man & 25 & 0 & 0 & 0 \\
\hline 2 & Woman & 62 & 3 & 0 & 0 \\
\hline & Amount & 87 & 3 & 0 & 90 \\
\hline
\end{tabular}

Table 6. Normal norm 6-minute walking test (meter) [6]

\begin{tabular}{|c|c|c|c|}
\hline \multirow{2}{*}{ No } & \multirow{2}{*}{ Status } & \multicolumn{2}{|c|}{ Gender } \\
\cline { 3 - 4 } & & Man & Woman \\
\hline 1 & $60-64$ & $558-672$ & $498-604$ \\
\hline 2 & $65-69$ & $512-640$ & $457-581$ \\
\hline 3 & $70-74$ & $498-622$ & $439-562$ \\
\hline 4 & $75-79$ & $430-585$ & $393-535$ \\
\hline 5 & $80-84$ & $407-553$ & $352-494$ \\
\hline 6 & $85-89$ & $347-521$ & $311-366$ \\
\hline 7 & $90-94$ & $280-457$ & $251-402$ \\
\hline
\end{tabular}

The normality test used One-Sample KolmogorovSmirnov Test. Data is normally distributed if $\mathrm{p}>0.05$. Below is the result of Kolmogorov Smirnov normality test which covered waist size, hip circumference, RLPP and 6 minutes walk.

Table 7. Research variable normality test

\begin{tabular}{|c|c|c|c|c|c|}
\hline \multicolumn{6}{|c|}{ One-Sample Kolmogorov-Smirnov Test } \\
\hline & & & Hip & RLPP & 6 \\
\hline & & Waist Size & Circumference & & $\begin{array}{c}\text { minutes } \\
\text { walk }\end{array}$ \\
\hline \multicolumn{2}{|l|}{$N$} & 90 & 90 & 90 & 90 \\
\hline \multirow{3}{*}{$\begin{array}{l}\text { Normal } \\
\text { Parameters }\end{array}$} & Mean & 88.9556 & 98.0667 & .9060 & 372.81 \\
\hline & Std. & 11.10614 & 8.43987 & .06618 & 83.298 \\
\hline & Deviation & & & & \\
\hline \multirow{3}{*}{$\begin{array}{l}\text { Most Extrem } \\
\text { Differences }\end{array}$} & Absolute & .064 & .074 & .093 & .091 \\
\hline & Positive & .060 & .074 & 0.60 & .088 \\
\hline & Negative & -.064 & -.070 & -.093 & -.091 \\
\hline \multicolumn{2}{|l|}{ Test Statistic } & .064 & .074 & .093 & .091 \\
\hline \multicolumn{2}{|c|}{ Asymp. Sig. (2-tailed) } & $.200^{c, d}$ & $.200^{c, d}$ & $.051^{c}$ & $.063^{c}$ \\
\hline \multicolumn{6}{|c|}{ a. Test distribution is Normal. } \\
\hline \multicolumn{6}{|c|}{ b. Calculated from data. } \\
\hline \multicolumn{6}{|c|}{ c. Lilliefors Significance Correction. } \\
\hline \multicolumn{6}{|c|}{ d. This is a lower bound of the true significance. } \\
\hline
\end{tabular}

The One-Sample Kolmogorov-Smirnov Test shows that all data variables, i.e. waist size, hip circumference, and 6 minutes walk has normal data distribution. All data is normally distributed, so that Pearson's correlation test was performed to determine whether there is any relation between anthropometric status and physical fitness.

$\mathrm{P}<0.05$ indicates a significant correlation between waist size, hip circumference, RLPP and physical fitness. The data above shows that all research variables, i.e. waist size, hip circumference and RLPP is $\mathrm{p}<0.05$, in which the waist size is $p=0.678$, hip circumference $\mathrm{p}=0.391$ and RLPP 0.537 . It's concluded that there is no 
relation between waist size, hip circumference and waist size to hip circumference ratio and physical fitness status in the elderly.

\section{DISCUSSION}

Physical fitness is an important benchmark for human health at every age group, including old age. Someone with a good physical fitness level also has high effectiveness and productivity. Aside from preventing injury due to every day physical activities, physical fitness also can improve the effectiveness and productivity of the elderly. Elderly people will be healthier and more independent. In the present study, the measured physical fitness components were cardiorespiratory fitness, flexibility, strength (hand, leg and back) and balance [7]. Physical activities such as exercises have great benefits because they can improve elements of physical fitness, i.e. cardiovascular and respiratory systems, joint flexibility and muscle strength. Exercise can reduce the occurrence and severity of cardiovascular diseases, obesity, DM, hypertension, some joint, muscle and bone disorders, and stress.

The research results showed that men had poor cardiorespiratory fitness, very good flexibility, poor hand strength, poor leg strength, poor back strength and poor balance. Meanwhile, women had poor cardiorespiratory, very good flexibility, poor hand strength, poor leg strength, poor back strength and moderate balance. Very good flexibility would help elderly people prevent injury during every day physical activities. Meanwhile, poor muscle strength, balance and cardiorespiratory fitness might have occurred because the exercises performed by the elderly people had low effects on muscle strength and cardiorespiratory components. It's been found that regular physical activity can reduce the prevalence of metabolic syndromes and improve physical fitness and health of the elderly [8].

Although the result of the present study didn't show any significant relation between anthropometric measurements and cardiorespiratory fitness, it should be noted that the cardiorespiratory fitness level of both male and female elderly people was low. The research result could be used to advise elderly people to maintain their cardiorespiratory fitness by performing various physical activities.

The elderly needs a special attention in terms of health and social issues. The physical activity, fitness level, physiological function and health of the elderly will lower over time. Physical fitness can be improved with regular physical activity [8]. Regular physical activity also can improve health and prevent diseases [9]. Some studies show that adults who are more physically active are healthier and have higher physical fitness than nonactive adults in various countries and population groups [7]. Therefore, physical activities were highly recommended to improve health and physical fitness as an application of healthy lifestyle. A study also showed that physical fitness can affect fitness and health and they have a mutual relation [7].

\section{CONCLUSION}

The research result shows no relation between waist size, hip circumference and waist size to hip circumference ratio and physical fitness status in the elderly. However, maintaining health with good diet and exercise is important to prevent obesity which can lead to various degenerative diseases.

\section{ACKNOWLEDGMENTS}

The authors would like to thank the Faculty of Sport Science of Universitas Negeri Yogyakarta for providing the research grant for the present study.

\section{REFERENCES}

[1] Taylor Denise, 2014. Review: Physical activity is medicine for older adults. Postgrad Med J 2014; 90:26-32.

[2] Katzmaryk. 2003. Targeting the metabolicsyndrome with exercise: evidence from the heritage family study. Medical, Science and Sport Exercise Journal, 35, (10), 1703-9.

[3] Rennie KL. Association of the metabolic syndrome with both vigorous and moderate physical activity. International Journal of Epidemiology. 2003; 32: 600-6.

[4] Werner W. K. H. and Sharon A. H. (2011). Lifetime Physical Fitness and Wellness. Wadsworth: United State of America.

[5] Dwyer, G.B. and Davis, S.E. (2008). ACSM's Health Related Physical Fitness Assessment Manual. American College of Sport Medicine: USA.

[6] Jones C.J., and Rikli R.E. (2002). Measuring Functional Fitness Of Older Adults, The Journal on Active Aging, March April 2002, pp. 24-30.

[7] Kuh D, Bassey EJ, Butterworth S, Hardy R, Wadsworth ME. (2005). Grip strength, postural control, and functional leg power in a representative cohort of british men and women: associations with physical activity, health status, and socioeconomic conditions. J Gerontol A BiolSci Med Sci. 2005;60(2): 224-31.

[8] Setiawan et al. (2018). Correlation Physical Activity, Energy Balance, and Metabolic Syndrome of Physical Fitness in Elderly Age Group. Majalah Kedokteran Bandung, Volume 50 No. 1, Maret 2018.

[9] Blair SN, Church TS. (2004). The fitness, obesity, and health equation: is physical activity the common denominator? JAMA. 2004; 292(10):1232-4. 